\title{
Manufactura artesanal de papel
}

\section{Artesanal paper manufacturing}

RAMÍREZ-ROMÁN, Adolfo†* SUÁREZ-ÁLVAREZ, Ángel, RODRÍGUEZ-RODRÍGUEZ, Luis Alberto y CHABAT-URANGA, Jacqueline

Universidad Veracruzana, Facultad de Ingeniería Mecánica y Ciencias Navales, México.

ID $1^{\text {er }}$ Autor: Adolfo, Ramírez-Román / ORC ID: 0000-0002-3820-8582, Researcher ID Thomson: S-5868-2018, arXiv Author ID: adolramirez, CVU CONACYT ID: 244749

ID 1 ${ }^{\mathrm{er}}$ Coautor: Ángel, Suárez-Álvarez / ORC ID: 0000-0002-0726-9630, CVU CONACYT ID: 946964

ID $2^{\text {do }}$ Coautor: Luis Alberto, Rodríguez-Rodríguez / ORC ID: 0000-0002-6118-040X, Researcher ID Thomson: W-93162019, CVU CONACYT ID: 1011993

ID $3^{\text {er }}$ Coautor: Jacqueline, Chabat-Uranga / ORC ID: 0000-0003-2202-1032, CVU CONACYT ID: 464993

DOI: $10.35429 /$ JIE.2020.12.4.13.29

Recibido Abril 15, 2020; Aceptado Junio 30, 2020

\section{Resumen}

El trabajo aborda en la factibilidad de un taller de manufactura recicladora de papel artesanal en la Facultad de Ingeniería Mecánica y Ciencias Navales de la Universidad Veracruzana, Región Veracruz; creando papel artesanal con residuos de hojas que ya fueron utilizadas en trámites administrativos y académicos, creando un impacto sostenible en sus tres dimensiones (social, económico y ambiental) en sus actividades operativas. Se realizó investigación cualitativa revisando proyectos desarrollados en otras instituciones, observando el entorno para conocer las necesidades y dificultades de operación, que involucra elementos técnicos y de costos. El análisis financiero concluye que la implementación de este proyecto requiere de una inversión inicial que involucra equipo y utensilios impactando en actividades de vinculación, de servicio social y para el programa institucional de formación Dual. La manufactura de una recicladora de papel artesanal es factible con beneficios académicos y de impacto social a corto plazo, con base en los indicadores del proyecto e investigaciones en prácticas académicas en temas de distribución de planta, ergonomía, control calidad, investigación de operaciones, seguridad, de administración y comercialización.

\begin{abstract}
The work addresses the feasibility of a proposal to recycle handmade paper at the Faculty of Mechanical Engineering and Naval Sciences of the University of Veracruz, Region Veracruz; creating handmade paper with leaf residues that were already used in administrative and academic procedures, creating a sustainable impact in its three dimensions (social, economic and environmental) in its operational activities. Qualitative research was carried out reviewing projects developed in other institutions, observing the environment to know the needs and difficulties of operation, which involves the plan and proposal of technical and financial analysis. The financial analysis concludes that the implementation of this project requires an initial investment that involves equipment and tools impacting on linking activities, social service and the Dual Institutional Training Program. The manufacture of a handmade paper recycler is feasible with short-term academic and social impact benefits, based on project indicators and research on academic practices in plant distribution, ergonomics, quality control, operations research, safety, administration and marketing.
\end{abstract}

Reciclado, Manufactura, Papel

Recycle, Manufacture, Paper

Citación: RAMÍREZ-ROMÁN, Adolfo, SUÁREZ-ÁLVAREZ, Ángel, RODRÍGUEZ-RODRÍGUEZ, Luis Alberto y CHABAT-URANGA, Jacqueline. Manufactura artesanal de papel. Revista de Ingeniería Industrial. 2020. 4-12:13-29.

*Correspondencia al Autor (Correo Electrónico: adolramirez@uv.mx))

$\dagger$ Investigador contribuyendo como primer autor. 


\section{Introducción}

En la actualidad el ser humano está inmerso en un ambiente con diversas problemáticas con relación al medio ambiente con impacto a enfermedades respiratorias y de visibilidad, involucrando acciones negativas a la flora y fauna, los ecosistemas. Actualmente, se han creado campañas que apoyan la preservación del medio ambiente y con ello estrategias para crear procesos ecológicos que no afecten al ecosistema $o$ ser autosuficiente creando actividades que generen recursos para las actividades internas de la institución.

El nivel de desechos que producimos a nivel mundial se ha acelerado en las últimas décadas, pero no estamos dando una respuesta adecuada a ese problema. (Organización Británica Verisk Maplecroft).

El reciclaje de papel es un tema pertinente para la conservación y protección del medio ambiente, con proyectos de reciclaje influyendo en restaurar la contaminación del medio ambiente y crear conciencia en acciones sensibles en la preservación de la vida y ahorro de recursos.

El grupo especializado en análisis de riesgo reveló que a nivel mundial se producen más de 2.100 millones de toneladas de desechos cada año, lo que podría llenar más de 800.000 piscinas olímpicas. Tan solo un 16\% (323 millones de toneladas) de esa basura es reciclada. Estados Unidos es el país que produce más desechos por persona del mundo: tres veces más que la media global. Además, es una de las naciones desarrolladas con la menor capacidad de reciclaje. Alemania, por otro lado, se presenta como el país más eficiente. Aparte de EE. UU., Países Bajos y Canadá son algunos de los países con una mayor producción de basura del mundo (BBC News Mundo, 2019).

Los resultados del estudio británico muestran que Estados Unidos produce un $12 \%$ de los desechos mundiales o cerca de 239 millones de toneladas, aunque el país tiene solo un $4 \%$ de la población global. En comparación, China o India, que juntos constituyen alrededor de un tercio de la población mundial, generan $27 \%$ de los residuos globales.
Estas cifras revelan que los estadounidenses producen en promedio tres veces más desechos que una persona que vive en China y siete veces más que un residente en Etiopía.

Otros países como Indonesia y Brasil, que representan una proporción similar a la de Estados Unidos en la población global, producen cerca de un $10 \%$ menos basura que la primera potencia mundial (BBC News Mundo, 2019).

La industria papelera busca alternativas con métodos de reciclaje que se adapten a los requerimientos actuales en los ámbitos productivo y ambiental, asegurando buenas prácticas de establecer niveles óptimos de producción con impacto sostenible en la región, principalmente los problemas que implique la deforestación.

El reciclaje es un método para recuperar parte de lo consumido de modo de poder transformarlo hasta que vuelva a ser de utilidad. En este sentido, el reciclaje de papel es una de las formas más comunes y divulgadas de reutilización de un material que no es infinito.

Cuando hablamos de reciclar el papel hacemos referencia al importante proceso mediante el cual una persona puede transformar el papel ya utilizado, en material que puede volver a servir originalmente y con más usos. El papel es un producto que toma como principal materia la celulosa obtenida de los árboles de variado tipo.

En 2015, la ONU autorizó la Agenda 2030 sobre el Desarrollo Sostenible, una oportunidad para que los países y sus sociedades inicien un nuevo camino con el que renovar la vida de todos, sin dejar a nadie atrás. La Agenda cuenta con 17 Objetivos de Desarrollo Sostenible, que incluyen desde la eliminación de la pobreza hasta la lucha al cambio climático, la educación, la igualdad de la mujer, la protección del medio ambiente o el diseño de nuestras ciudades (Naciones Unidas, 2019). Por lo tanto, en el objetivo 15: Gestionar sosteniblemente los bosques, luchar contra la desertificación, detener e invertir la degradación de las tierras y detener la pérdida de biodiversidad. 
El $30.7 \%$ de la superficie terrestre está cubierta por bosques y estos, además de proporcionar seguridad alimentaria y refugio, son fundamentales para combatir el cambio climático, pues protegen la diversidad biológica y las viviendas de la población indígena. Al proteger los bosques, también podremos fortalecer la gestión de los recursos naturales y aumentar la productividad de la tierra.

Actualmente, 13 millones de hectáreas de bosque desaparecen cada año y la degradación persistente de las zonas áridas está provocando además la desertificación de 3600 millones de hectáreas. Aunque un $15 \%$ de la tierra se encuentra actualmente bajo protección, la biodiversidad aún está en riesgo. La deforestación y la desertificación, provocadas por las actividades humanas y el cambio climático, suponen grandes retos para el desarrollo sostenible y han afectado la vida y los medios de vida de millones de personas en la lucha contra la pobreza (Naciones Unidas, 2019).

El trabajo ha de contribuir al cuidado del medio ambiente, mencionando los problemas actuales y explicando temas fundamentales del proceso de manufactura de reciclaje artesanal.

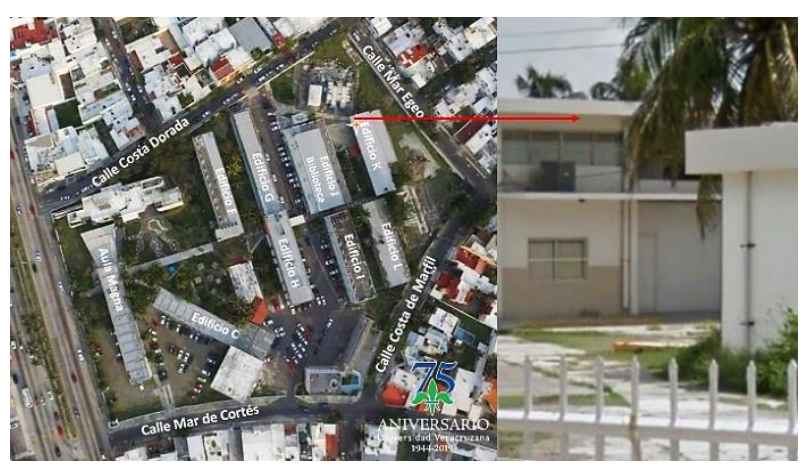

Figura 1 Edificio K Facultad de Ingeniería Mecánica y Ciencias Navales (Universidad Veracruzana - Región Veracruz)

Fuente: Elaboración propia

Se describe trabajo de una recicladora de papel artesanal en el edificio K de la Facultad, considerando costos para la inversión y su factibilidad, las cotizaciones de maquinaria y gastos en general. Creando valor en la actividad de disposición final de un residuo domestico académico con utilidad económica, aprendizaje y concientización social - ambiental.
Recurrir al reciclaje de papel es una actividad importante ya que permite reutilizar una gran parte de material que de otro modo se desecharía sin tanto problema y sin conciencia de los daños que día a día se generan.

Por lo tanto, realizar un estudio de factibilidad para transformar el papel de desecho en papel artesanal mediante operaciones y técnicas tradicionales para contribuir a la preservación del medio ambiente de la región, el cual, se desarrollará en el presente artículo los siguientes elementos:

Entorno y desarrollo industrial donde se indica breve historia del papel artesanal, la fabricación del papel en la actualidad, su problemática, y el proceso de reciclaje artesanal.

Tipos de equipo para el reciclado de papel.

Método de reciclaje de papel a través de las técnicas artesanales y otros usos a los deshechos de papel. localización.

Ubicación adecuada en base a factores de

Cotizaciones de los equipos que se utilizaran para el proceso de reciclado.

Una recicladora de papel artesanal a través de transformar desechos de papel proveniente de casas, empresas, escuelas, etc., para que las personas puedan contribuir al cuidado del medio ambiente.

\section{Entorno y desarrollo industrial}

El papel ha existido desde tiempos remotos en todas partes del mundo no importando condición social o religión, ya que el hombre busca plasmar sus ideas y sentimientos gráficamente, siendo un material esencial en la vida cotidiana del ser humano. 
Joseph (2004), comenta que en la época de los hombres primitivos se plasmaban ideas de lo que deseaban decir en las paredes de las cavernas, más tarde en placas de mármol o bronce, después en tablillas de arcilla, caparazón de tortuga, huesos, madera o cera; pero según fue pasando el tiempo se hizo necesario tener otro tipo de material que fuera más fácil de manejar, por ejemplo: en el Mediterráneo el papiro, en América el papel precolombino y en el Extremo Oriente el papel como se conoce en la actualidad.

El papiro (ver Figura 2) fue usado por la cultura egipcia 3,200 años antes de Cristo, es una planta que crece en las orillas de algunos ríos africanos y su nombre científico es Cyperus papyrus, las propiedades de esta planta permiten trabajar sus hojas de modo que pueden formar superficies continuas muy estables y amplias, con características muy parecidas del papel tradicional.

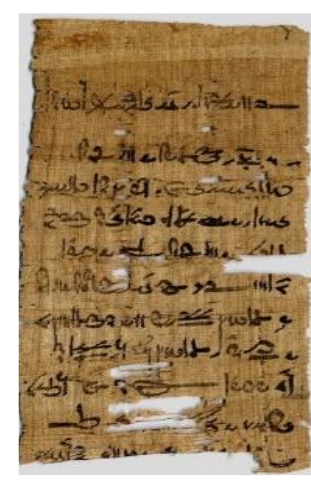

Figura 2 El papiro

Fuente: https://redhistoria.com

El papel pergamino se desarrolló en América mucho antes que llegaran los conquistadores españoles. Se cree que los Incas de las cordilleras sudamericanas, probablemente, utilizaron fibras vegetales autóctonas para fabricar un papel semejante al papiro.

Antes de la invención del papel, según una leyenda, un poderoso general chino llamado Moung-Tian conoció el papiro egipcio y pidió a sus artesanos que buscaran entre las plantas de su país una especie similar, pero no se obtuvieron los resultados esperados. Tres siglos después, de los ensayos encargados por MoungTian, el primer papel de la historia lo logró crear Tsin-Lun a partir de fibras vegetales extraídas de trapos, redes de pescar, corteza de morera, ramio, cáñamo o bambú en el año 105 d.C.
Para el año 751 en Turquestán, el mismo autor reporta que los árabes apresan a unos chinos fabricantes de papel y consiguen arrancarles su secreto, es así como se empezó a expandir a través de Asia hasta alcanzar Occidente (ver Figura 3), después de Samarcanda la expansión llega hasta Europa gracias a la cultura del islam. Desde Europa se exportó a América. En el siglo XVII el papel ya se conocía en todo el mundo.

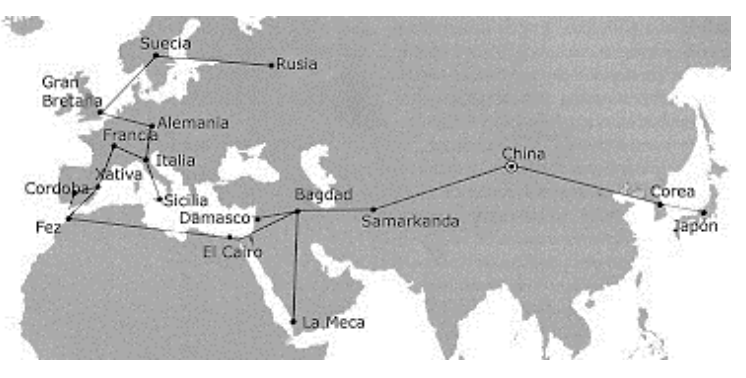

Figura 3 Expansión del papel en el mundo Fuente: Martínez Barbosa, G. L., (2008)

Escoto (2006), menciona que el principio técnico de la formación del papel consistía primero en la obtención de la pulpa, posteriormente se continuaba con el batido y preparación de la pulpa, una vez hecho lo anterior, se procedía a la formación de la hoja en un marco de bambú recubierto con cedazos, el cual se sumergía en la suspensión fibrosa, se drenaba por gravedad a través de los orificios del cedazo, permitiendo que las fibras formaran un tramado o colchón fibroso sobre la superficie del cedazo o malla; de esta manera quedaba consolidada un hoja húmeda (ver Figura 4); y finalmente el secado de la hoja de papel se hacía mediante eliminación del agua por exprimido o prensado y luego mediante fijación de la hoja en una superficie lisa exponiéndola al medio ambiente.

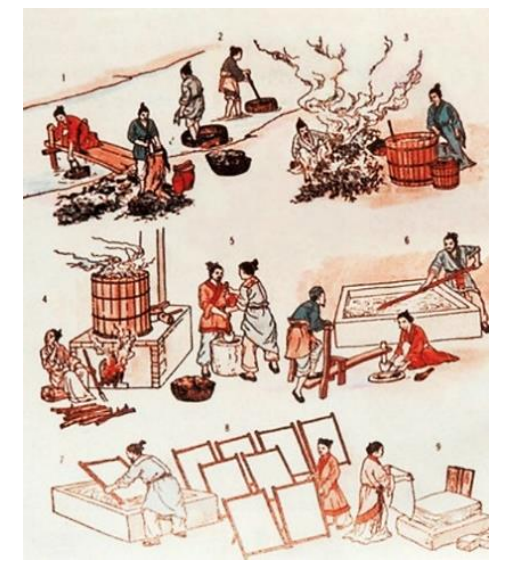

Figura 4 Formación de la hoja de papel Fuente: Cátedra de Historia Naval / Universidad de Murcia

RAMÍREZ-ROMÁN, Adolfo, SUÁREZ-ÁLVAREZ, Ángel, RODRÍGUEZ-RODRÍGUEZ, Luis Alberto y CHABAT-URANGA, Jacqueline. Manufactura artesanal de papel. Revista de Ingeniería Industrial. 2020 
Sanjuán (1997), comenta que la primera fábrica de papel de la historia fue instalada por Tsai-Lun en la provincia de Honan en el año 105 d.C., en China. Hasta finales del siglo XV1l, la fabricación de papel no pasó de ser una labor artesanal, siguiendo la técnica de los chinos de formar hojas en bastidores. Por lo que para el año 1799 el Francés Nicolás Louis Robert inventó una maquina continua para hacer papel (ver Figura 5), para el año de 1803 los hermanos Fourdrinier, ingleses, adquirieron la patente de Louis Robert y perfeccionaron la máquina.

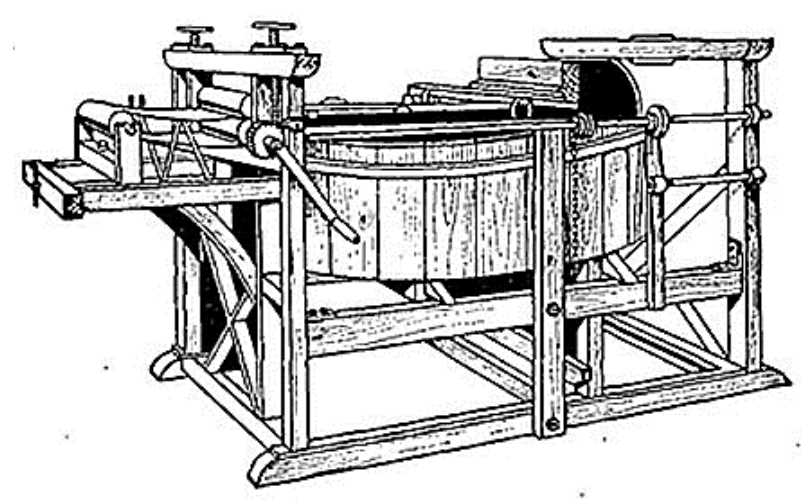

Figura 5 Máquina de papel de Louis Robert Fuente: http://venezia.od.ua/

La significación que el papel tuvo entre las civilizaciones antiguas de México, son muy carentes los datos que los primeros cronistas transmitieron acerca de los procedimientos para fabricarlo. Hernández (1943), comenta que se fabricaba papel de maguey (metl), de algodón (ixcotl), de la planta llamada izote (izotl), del amaquahuitl (árbol de papel), del Amate (amatl) y de algunos otros de la corteza de algunos árboles o de su raíz, pero se puede deducir que los principales elementos para fabricar papel se tomaban del maguey y del amatl, pudiéndose utilizar otras fibras según su presencia y abundancia.

Así mismo, este autor describe que para la fabricación del papel sólo se cortaban las ramas gruesas de algunos árboles (amate), dejando los renuevos; se ablandaban en agua y se dejaban remojar durante una noche en los arroyos o corrientes de agua, al día siguiente se les arrancaba la corteza, y después de limpiarla de la cutícula superior, se extendía a golpes con una piedra plana pero surcada de estrías, de esta manera el material se volvía flexible; se cortaban en pequeños trozos que, golpeados de nuevo por diferentes lados con otra piedra más plana, se unían fácilmente entre sí, por último se alisaban y se formaban en hojas de papel de $44.36 \mathrm{~cm}$ de largas y $33.27 \mathrm{~cm}$ aproximadamente de ancho.
Landa citado por Hernández (1943) hace mención en su obra, que los mayas tenían libros de corteza de 10 a 12 varas $(8.38$ a $10.05 \mathrm{~m})$ de largo, doblados en piezas de $0.21 \mathrm{~m}$ cada doblez. Por otro lado, también menciona que los mexicas hacían papel amatl o papiro de maguey, macerando por algún tiempo en agua las pencas y machacándolas después, para separar las fibras; éstas se extendían por capas, se les agregaba un tipo de goma y se le sujetaba a presión para que quedaran bien unidas.

Lenz (2001), indica que para finales del siglo XVI y principios del XVII, las reglas y limitadas disposiciones que tenía la Corona Española para la elaboración y comercio del papel prohibían cualquier tipo de taller o establecimiento que se dedicara a este tipo de actividad, por lo que esta actividad quedó estancada.

Transcurridos los siglos, al término de la lucha por la independencia, para el año de 1825 se instaló la primera máquina de papel en México y para el año de 1830 se logró promover la edificación de fábricas textiles de algodón y de papel. Más tarde, en el año de 1831 al no tenerse conocimiento de cómo operar las industrias papeleras, la maquinaria permanece almacenada durante varios años convirtiéndose en maquinaria obsoleta y de baja capacidad de producción. En 1890 se iniciaba la era de la madera como materia prima celulósica, de este tiempo para adelante las personas han constituido un gran número de sociedades dedicadas a la fabricación de cartón y papel.

El mismo Lenz (2001) agrega que al finalizar el siglo XIX, México contaba con seis pequeñas fábricas de papel y para el año 2004 contaba con las mismas seis plantas de celulosa y papel y 57 plantas de papel, fábricas que proporcionan empleo directo y permanente a las personas. Por otro lado, Sanjuán (1997), menciona que en tiempos prehispánicos el papel era utilizado principalmente como objeto ritual, ornamental y particularmente era muy valioso. Para esto, los mayas ya fabricaban papel (ver Figura 6) en los años 600 y utilizaban corteza de un árbol llamado huun, al igual que vestían túnicas de papel que fabricaban a partir de cortezas de higuerilla, atuendo que posteriormente les servía para la confección de libros, y sus códices eran pintados en papel de henequén. 


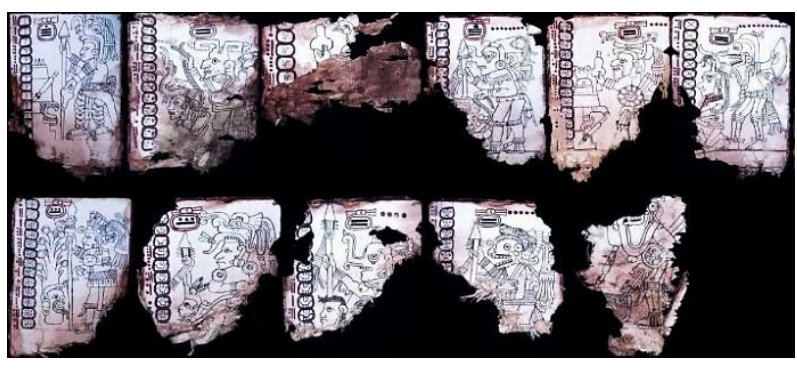

Figura 6 El papel en tiempos prehispánicos Fuente: https://www.ancientpages.com/

Hay fábricas en más de 100 países repartidos por todo el mundo, con más de 3,5 millones de personas empleadas en forma directa.

Los mayores productores de pasta y papel son Estados Unidos, Canadá, Japón, China, Finlandia, Suecia, Alemania, Brasil y Francia. A pesar de las predicciones de disminución del consumo de papel ante el auge de la era electrónica, desde 1980 se observa un crecimiento constante de la tasa anual de producción del 2,5\%. Además de sus ventajas económicas, el consumo de papel tiene el valor cultural inherente a la función que desempeña en el registro y difusión de la información. Por esta razón, la tasa de consumo de pasta y papel se ha utilizado como indicador del desarrollo socioeconómico de una nación.

La principal fuente de fibra para la producción de pasta en este siglo ha sido la madera procedente de los bosques de coníferas, aunque en los últimos años ha aumentado la utilización de bosques tropicales y boreales. La presión ejercida por los grupos ecologistas para la conservación de los recursos forestales, manifestada en la defensa del empleo de papel reciclado, de cultivos agrícolas y de bosques de plantación de rápida rotación como fuentes de la materia prima, puede modificar la distribución de las instalaciones de producción de pasta y papel en todo el mundo en las próximas décadas. (academia.edu, 2019).

Sin embargo, los problemas medioambientales asociados a la producción de papel se describen a continuación:

Consumo de madera: Se consumen bosques enteros, los más utilizados son el de pino o eucaliptos, este problema se reduce hoy por la reforestación de las zonas con especies destinadas a este fin.
Liberación de $\mathrm{CO}_{2}$ (gas con efecto invernadero) por quema de la hojarasca, ramas y otras partes del árbol que no se usan.

Elevado consumo de agua (hasta $60 \mathrm{~m}^{3} /$ tonelada de pasta).

Vertidos. Presentan distintos tipos de contaminación:

- Partículas sedimentables y en suspensión.

- Sustancias que consumen oxígeno modificando DBO y DQO.

- Compuestos órgano clorado.

- Colorantes.

- Nutrientes (nitrógeno y fósforo) que conducen a la eutrofización de los cursos de agua.

- Sustancias tóxicas.

- Modificación del pH de los cursos de agua.

- Aumento de la temperatura del agua vertida.

- Compuestos de la madera (ácidos de la resina y ácidos grasos insaturados como oleico, linoleico, palmitoleico, etc.).

Emisiones atmosféricas: óxido sulfuroso, $\mathrm{SO}_{2}$, precursor de lluvia ácida, malos olores por sulfuros, partículas de hollín, monóxido de carbono, $\mathrm{CO}$, compuestos orgánicos volátiles, compuestos clorados, óxidos de nitrógeno, $\mathrm{NO}_{\mathrm{x}}$

Del total de residuos urbanos, el papel y cartón suponen entre el $16 \%$ y el $25 \%$, de los cuales se puede lograr recuperar hasta un $70 \%$. En su mayoría provienen de revistas y periódicos, de envases de productos alimenticios, cajas de cartón, papel de alta calidad utilizado en impresión y reproducción, y papel mezclado. (inforeciclaje.com, 2019).

La mayor parte de papel se fabrica a partir de árboles y anteriormente era obtenido de otras plantas, incluyendo el algodón, el cáñamo del que se extrae una celulosa de alta calidad, el helecho, el ajo, la cebolla o la ortiga. 
La industria papelera mundial consume alrededor de 4.000 millones de árboles cada año, principalmente pino y eucalipto. Con el reciclaje de papel y cartón se consigue alargar la vida de las fibras de celulosa, un recurso natural que procede de la madera.

El papel de desecho puede ser triturado y reciclado varias veces. Sin embargo, en cada ciclo del $15 \%$ al $20 \%$ de las fibras se vuelven demasiado pequeñas para ser utilizadas. Además, se calcula que alrededor de un $19 \%$ del papel que utilizamos no puede recuperarse para su reciclaje porque lo guardamos, como puede ocurrir con los libros, las fotografías o los documentos, o debido a su uso como sucede con el papel higiénico y sanitario o con el papel de fumar. Por eso es necesario inyectar permanentemente una cierta cantidad de fibra virgen en el proceso. (ecoagricultor.com, 2019).

Por lo anterior, y disminuir el impacto negativo ambiental se tiene generalmente los siguientes pasos de reciclaje de papel:

- Recogida selectiva del papel usado en contenedores especiales.

- Depuración de la pasta de papel usado mediante filtrado y centrifugado, para eliminar las posibles partículas de elementos ajenos a la fibra como arenas, lacas, alambres, cuerdas, etc.

- Separación de la tinta mediante flotación. Para ello la pasta se sumerge en agua jabonosa (surfactantes) en un tanque, denominado también púlper o tina de mezcla, y se inyecta aire para provocar la aparición de burbujas. La tinta forma una suspensión coloidal y se consigue que la espuma flote junto con la tinta permitiendo su separación mecánicamente. Posteriormente la tinta se traslada a vertederos, donde se incinera con el empleo de su propia energía calorífica.

- Secado y prensado. La pasta obtenida, que suele contener un $42 \%$ de fibra, sigue el mismo proceso que la celulosa de origen primario para la obtención del papel. Es decir, se seca a $120^{\circ} \mathrm{C}$, al mismo tiempo que se prensa y se estira para darle la forma y textura final.
Con referencia al proceso artesanal del papel (Museu Molí Paperer de Capelladas), se describen las siguientes actividades: cuando llegan los bloques de papel se limpian, clasifican, parten en pequeños trozos y se echan en un recipiente llamado pudridero, dónde se mezclan con agua para que se vayan descomponiendo. Para que este proceso se acelere se añade un producto alcalino como ceniza o cal apagada, además de conferir un blanqueamiento extra. Una vez que están los bloques de papel descompuestos (el tiempo depende de la materia del papel, del agua...) se pasan a una tina, de ahí también le viene el nombre a este papel artesanal de "papel de tina".

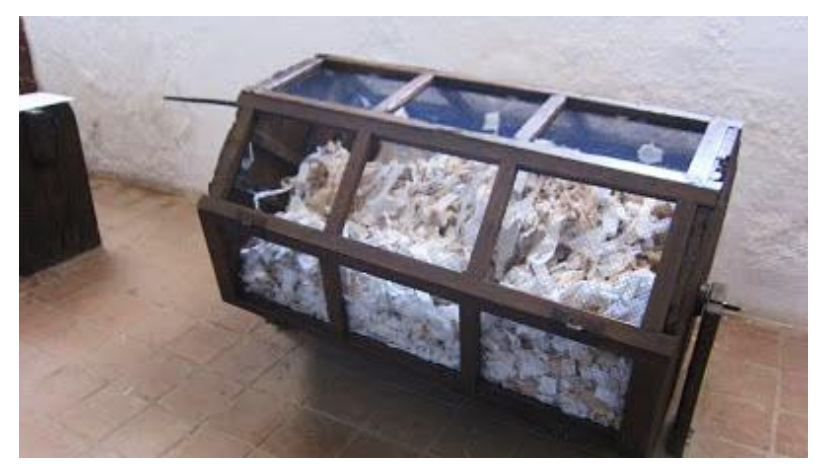

Figura 7 Limpieza y aireación de papel Fuente: Museu Molí Paperer de Capelladas

En la tina se mezclan con más agua y se bate con unos mazos de madera, llamados batanes, estos se mueven por la acción del agua que mueve la rueda del molino, para desleír y dispersar bien las fibras.

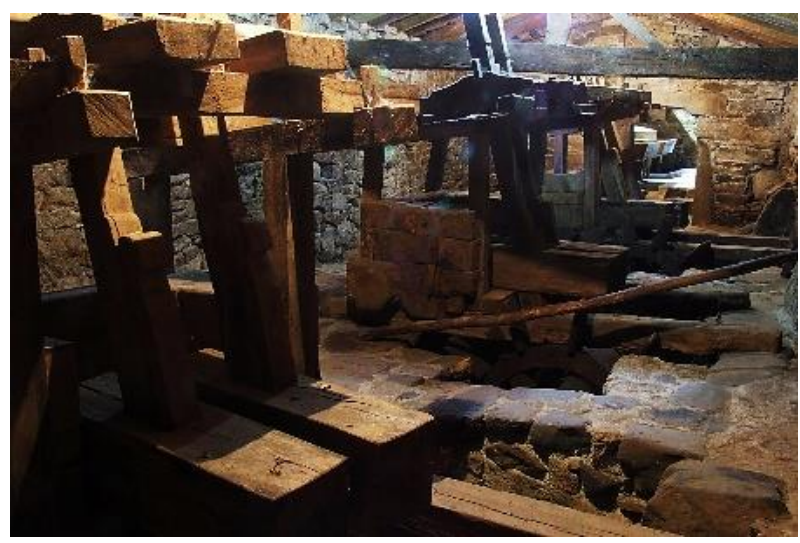

Figura 8 Batanes en funcionamiento

Fuente: Museu Moli Paperer de Capelladas

Cuando la pulpa adquiere un aspecto lechoso se pasa a la formación de hojas. Dependiendo del grosor de las hojas que se vaya a fabricar se añade más o menos agua a la pulpa. 
Para extraer la pulpa se utilizaba un cedazo rectangular o formadora que está compuesta de una rejilla de hilo muy fino de cobre o de latón. Estos hilos se disponen de manera horizontal y vertical (puntizones y corondeles) sobre un marco de madera. Esta trama queda marcada en el papel al depositarse menos pulpa sobre el relieve, se denomina verjura y a este papel se le conoce con el nombre de "papel verjurado".

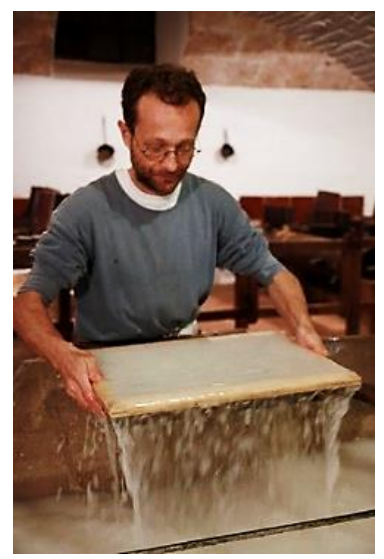

Figura 9 Fabricación de hoja

Fuente: Museu Moli Paperer de Capelladas

En el siglo XIII en Italia aparece la filigrana que es un dibujo que se cose a la formadora con alambre y que identifica el molino papelero en el que se hizo ese papel. Esta marca se ve al trasluz o a simple vista. En España la primera filigrana se cree que procede de Játiva.

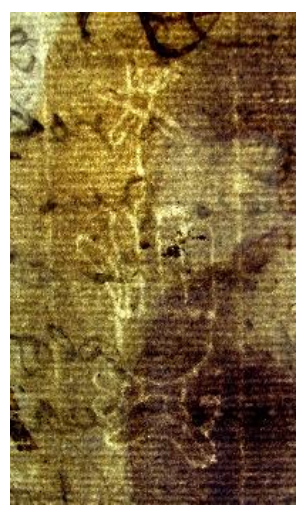

Figura 10 Verjura y filigrana, siglo XVI Fuente: Cristina Romero Manso

La formadora se complementa con un marco o moldura interior de madera que se encaja impidiendo el vertido de la pulpa lateralmente y regulando el grosor.
Ésta se introduce en la pila verticalmente, se coloca horizontalmente y se extrae; una vez extraída se mueve con un suave balanceo, para que la pulpa quede bien distribuida, se escurre, levanta el marco y vuelve sobre un sayal húmedo. A partir de aquí, se van colocando unas encima de otras. Tras conseguir la altura deseada se pasan al prensado dónde se elimina parte del agua.

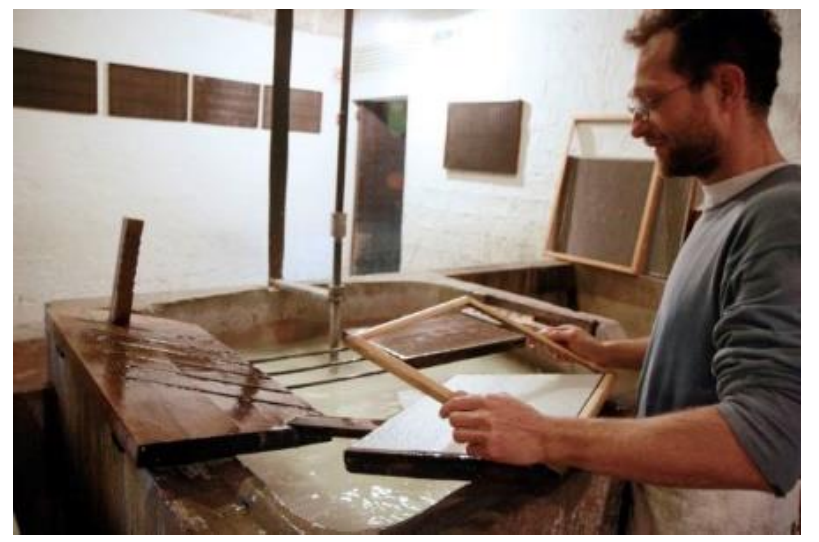

Figura 11 Hoja formada

Fuente: Museu Molí Paperer de Capelladas

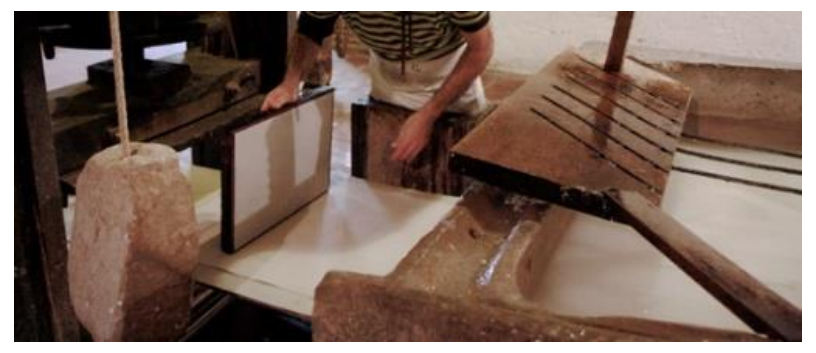

Figura 12 Colocando en sayal Fuente: Museu Moli Paperer de Capelladas

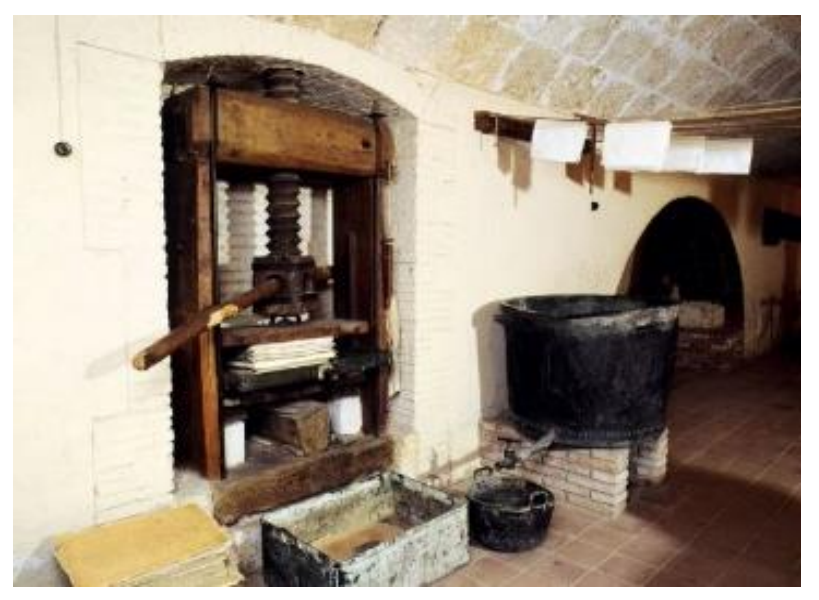

Figura 13 Prensado y encolado Fuente: Museu Moli Paperer de Capelladas

Las hojas de papel ya formado se pasan al secado dónde se orean sobre una superficie plana en un primer momento y después de manera vertical en el tendedero para secarse al aire o incluso blanquearlas al sol. 


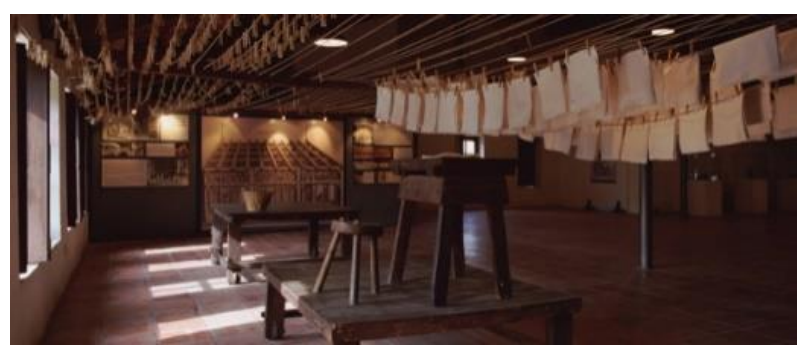

Figura 14 Tendido de Papel

Fuente: Museu Molí Paperer de Capelladas

En el caso de papeles muy absorbentes después del secado, finaliza el proceso. Estos papeles son aptos para lápiz, carbón, sanguina, etc., están sin encolar, pero la aplicación de tinta hace que se emborrone. Por eso hay otros papeles aptos para la tinta que necesitan ser encolados para que aumente su resistencia e impermeabilidad. El encolado tradicional era el de cola animal o gelatina aplicada mediante brocha o por baño. Una vez encoladas se vuelven a prensar, más suavemente y se separan para su secado. El encolado sirve para unir las fibras y darle ese sonido característico que posee el papel al agitarlo, llamado "carteo".

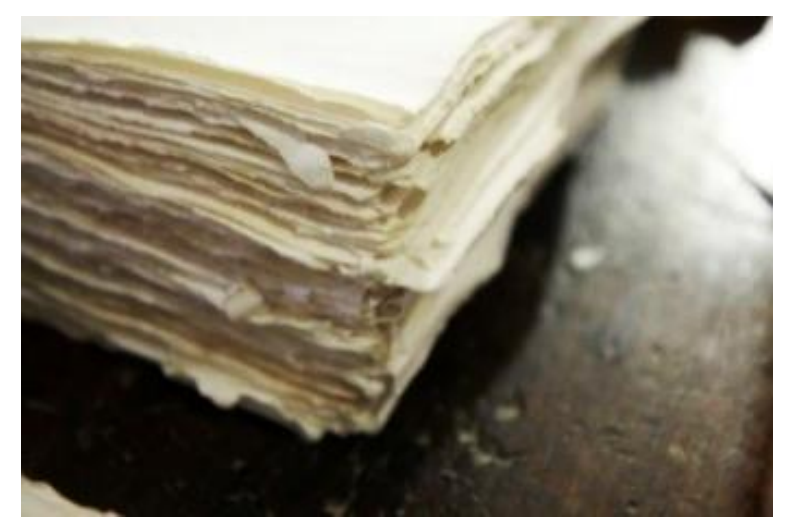

Figura 15 Conjunto de hojas

Fuente: Museu Molí Paperer de Capelladas

El proceso final es el de bruñido o satinado, que se realizaba por medio de un hueso o piedra y después se sustituyó por mazos satinadores y cilindros de acero que transmiten más brillo, fuerza y consistencia.

Por último, se corta y desbarba. Finalizado este proceso está listo para embalar y vender. Normalmente en resmas (500 hojas).

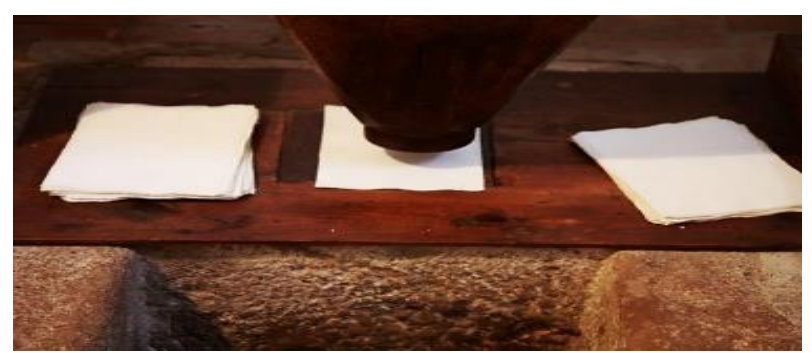

Figura 16 Mazo satinador

Fuente: Museu Molí Paperer de Capelladas

El papel hoy en día se debe considerar como un arte milenario donde el fundamento básico de su elaboración, es drenar una suspensión de fibras a través de una malla; por lo que el papel se hace un instrumento esencial para el desarrollo y la mejor comunicación entre las poblaciones, ya que la técnica se modifica y se adapta a cada lugar, produciéndose una gran diversidad de métodos para la elaboración de papel.

\section{Maquinaria y equipo}

Una máquina de reciclaje es un aparato creado por el hombre para automatizar el proceso de reciclaje de diferentes tipos de residuos. Existen máquinas para reciclaje casero, que son las que crean las personas en sus hogares, y también están las usadas por empresas y multinacionales.

En la industria de la ecología existen tipos de maquinaria para reciclaje, se clasifican principalmente en cuatro tipos: compactadoras, retro compactadoras y prensas de reciclaje vertical y horizontal.

Una de las máquinas de reciclaje más usadas en el mundo del reciclaje son las compactadoras. Estas dotan a las empresas de reciclaje de una forma fácil y rápida de reutilizar, compactar/aplastar y dar forma al plástico, cartón y otros materiales en comparación al reciclaje hogareño.

A diferencia de las compactadoras manuales o estáticas, las retro compactadoras de reciclaje son aquellas que automatizan todo el proceso de compactar la basura orgánica e inorgánica. 


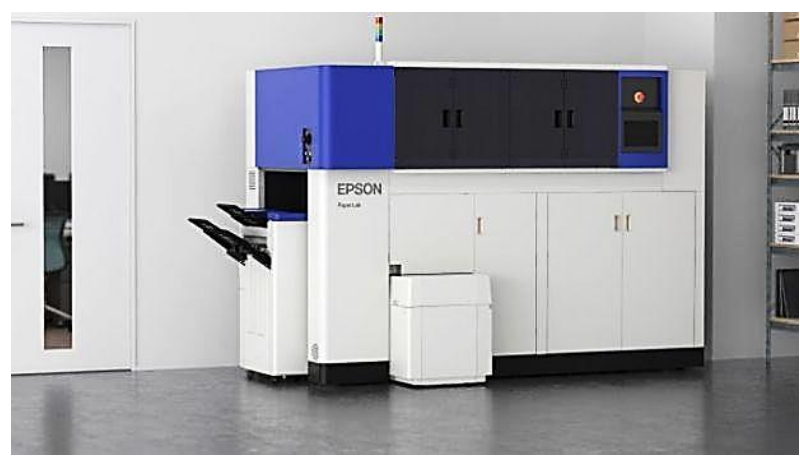

Figura 17 Primera máquina recicladora de papel Fuente: https://informe21.com/

Las maquinas procesadoras permiten a las empresas de reciclaje procesar de forma automática: Cartón, cajas, plásticos, aluminio, residuos orgánicos.

Otra forma de compactar el material reciclable es utilizando prensas de reciclaje verticales.

Estas prensas de residuos sirven para justamente prensar, es decir, compactar y achicar al máximo el volumen de material que se pretende reutilizar.

Entre sus características encontramos:

- Máxima eficiencia energética pues consume poco y hacen mucho.

- Son pequeñas en tamaño, suelen ubicarse bien en casi cualquier ambiente.

- $\quad$ No emiten prácticamente ruido.

- No son tan caras como las maquinas retro compactadoras.

Existen diferentes tipos de prensas verticales como:

- Prensa de reciclaje hidráulica.

- Prensa multi-cajón.

- Prensa de basura.

- Prensa de botellas y latas.

Las prensas de reciclaje horizontal son otra de las formas de automatizar el reciclaje de productos. En comparación con las verticales, encontramos con que tienen mayor tamaño, y por lógica son más difíciles de distribuir en los espacios.

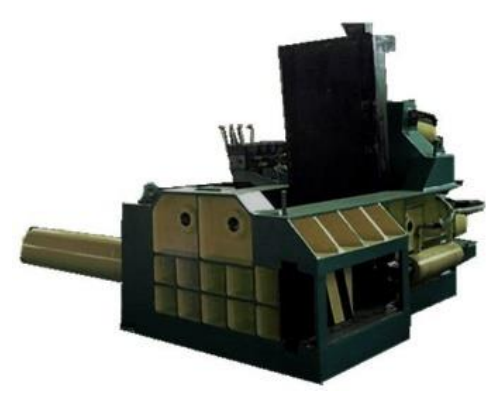

Figura 18 Prensa de reciclaje horizontal

Fuente: https://www.ecologiahoy.com

El reciclaje de cartón y papel es una de las actividades más populares dentro de las empresas de reciclaje.

Para ello se utilizan especializadas en comprimir, compactar y prensar papel y cartón, ideales para la reutilización y alivio del medio ambiente.

A nivel industrial existen otras máquinas para reciclar papel y cartón como:

Molino triturador compacto para papel y documentos: el cual permite lograr cortes, trituración y picado total del papel.

Molino triturador de alto rendimiento: el cual se utiliza para cortar, triturar, destrozar y romper papeles, guías, revistas, libros, etc.

Cortadora trituradora industrial para papel: también sirve para lo mismo, tritura, corta y destroza papel, libros, cartón, folletos, catálogos, guías, tarjetas, etc.

A nivel industrial existen todo tipo de máquinas especializadas en reciclaje que se usan en multinacionales, grandes fabricantes de electrónica, papel y otros materiales las usan, aunque no son las más comunes de ver en las empresas de reciclaje normales que todos conocemos.

Hoy existen máquinas para reciclar materiales textiles y tejidos, reciclar papel, fibra de vidrio, residuos sólidos urbanos, entre otros.

Estos aparatos de reciclaje industrial permiten reciclar, reutilizar y reducir al mismo tiempo. Hoy por hoy juegan un papel fundamental para tratar de remediar el impacto del hombre y toda la basura que genera en su día a día. 


\section{Método de reciclado}

El papel reciclado de fibras largas de celulosa (tales como papel de oficina) tiene mayor flexibilidad para el reciclado, ya que puede ser utilizado para producir nuevos productos de papel que utilizan cualquiera de las fibras largas o cortas. El papel recuperado con fibras de celulosa cortas (como periódicos) sólo pueden ser reciclados en otros productos que utilizan las fibras cortas de celulosa. Por esta razón, el papel recuperado con fibras largas es generalmente de mayor valor que el papel recubierto con fibra corta.

Por ejemplo, la industria papelera española utiliza como materia prima 1,8 millones de toneladas de fibra virgen y 5,1 millones de toneladas de fibra recuperada. Por cada tonelada de papel que se recicla, 17 árboles se salvan de su destrucción. (Biopappel y Ciceana MX, 2019).

Existe una gran variedad de materias primas para la elaboración de papel artesanal entre las que destacan materiales no leñosos como pajas, bambúes, bagazo, etc. Y residuos vegetales generados de actividades agrícolas e industriales.

Nuestra principal fuente de producción será el papel de desecho que ya ha sido utilizado en oficinas o aula de clases y normalmente se tira a la basura sin darle más uso y generando más contaminación. En general toda materia prima que se presente bajo forma de fibras de dimensión conveniente y que sean susceptibles de formar enlaces químicos entre ellas, es apta para la fabricación del papel.

Para lograr la extracción de la celulosa y obtener una pulpa idónea para la fabricación del papel se cocina la materia prima en una solución alcalina. La temperatura de reacción ha de ser la ebullición de la solución a presión atmosférica.

Es muy importante en esta etapa la cocción uniforme de las fibras, de manera que se suavicen y el papel tenga un acabado consistente. Cuando se haya completado la etapa de disgregación, la pulpa será llevada a la licuadora donde será triturada y mezclada de manera más uniforme para que tenga una consistencia más manejable.
La reacción de ser lavada completamente la pulpa así obtenida se coloca en un recipiente con agua y se agita para asegurar que se encuentra bien disuelta. Para la formación del papel se necesita un bastidor cuya función es la de contener la pulpa al retirarla del agua para darle forma a la hoja de papel. El bastidor está formado por el marco y el contramarco, dos piezas iguales que pueden confeccionarse con madera. Su tamaño dependerá del tamaño del papel que se quiera elaborar. En el marco se debe clavar la malla que servirá para recoger la pulpa; el contramarco no lleva malla.

Para hacer la hoja de papel artesanal se debe introducir el bastidor en el recipiente en forma vertical luego en forma horizontal $y$ esperar a que se forme una lámina de pulpa sobre éste. Una vez el grosor de la película sea el deseado, se debe retirar el bastidor del agua en forma horizontal y mientras se escurre mover el bastidor para fomentar el entrecruzamiento de las fibras. Cuando la hoja ha escurrido suficiente agua, se debe quitar el contramarco y desmoldar el papel artesanal sobre un paño de lienzo o algodón, presionando de los bordes del marco en forma pareja hasta que no expulse más agua.

Las hojas se someten a una prensa hidráulica de acuerdo con el espesor requerido, el cual, se debe cambiar la posición de las hojas en la prensa periódicamente. Al cabo del tiempo previsto se retira el papel todavía húmedo del lienzo y se completa el secado en un espacio con circulación de aire caliente.

Por último, cuando las hojas terminen su proceso de secado, se llevarán al área de almacenado que concluye en un área donde se mantendrán en un buen estado de acuerdo con sus propiedades.

\section{Resultados}

Los resultados obtenidos por el desarrollo de la investigación y su respectiva implementación se tienen las siguientes secciones con referencia a diagramas, ubicación, costos y descripción del taller recicladora de papel aplicado. 


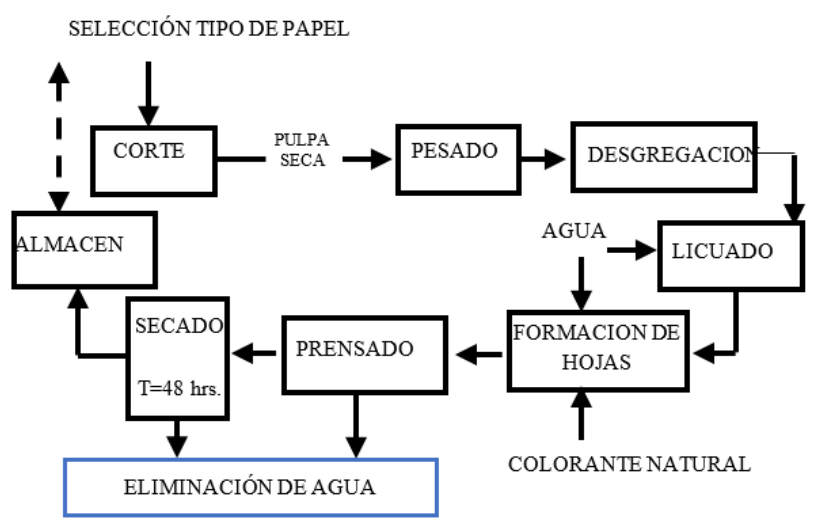

Figura 19 Diagrama de bloque del proceso de reciclado artesanal del papel

Fuente: Elaboración propia

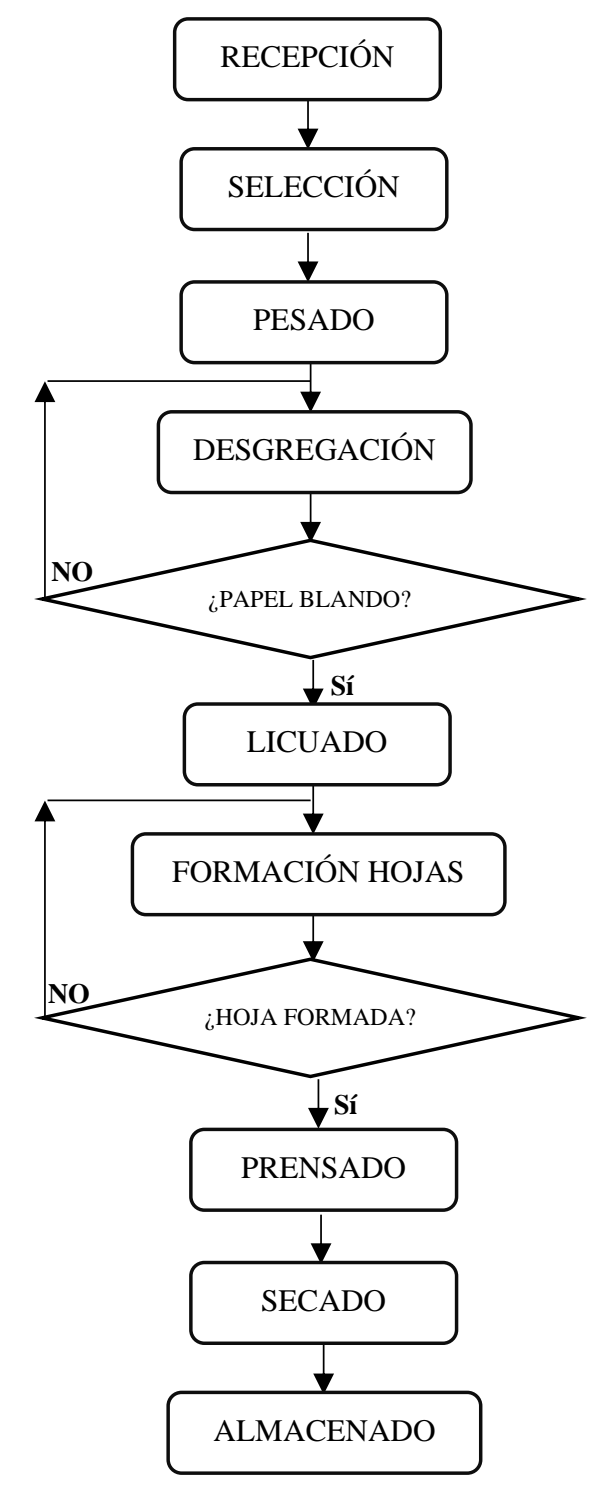

Figura 20 Diagrama de flujo del proceso artesanal Fuente: Elaboración propia

\section{Ubicación}

La ubicación del taller es un criterio muy importante de tomar en cuenta principalmente por sus implicaciones económicas.

La ubicación de la recicladora de papel artesanal se determinó mediante el análisis de diversos factores como: condiciones ambientales, disponibilidad de materia prima, servicios básicos y vías de acceso.

Se considera en el Edificio K planta baja de la Facultad de Ingeniería Mecánica y Ciencias Navales, en el Taller de Navales, Universidad Veracruzana, Región Veracruz.

Considerando los requerimientos de la recicladora de papel artesanal y que cumple con ellos, se considera un lugar indicado, ocupando un espacio que ha funcionado como almacén de muebles de desechos.

Se consideró los requerimientos de agua y de energía eléctrica.

Para el dimensionamiento de la planta se determinó de acuerdo con el tamaño de los equipos a utilizar en el proceso productivo propuesto. Posteriormente se diseñó el esquema más eficiente para aprovechar al máximo el espacio, sin dejar de lado la funcionalidad del diseño.

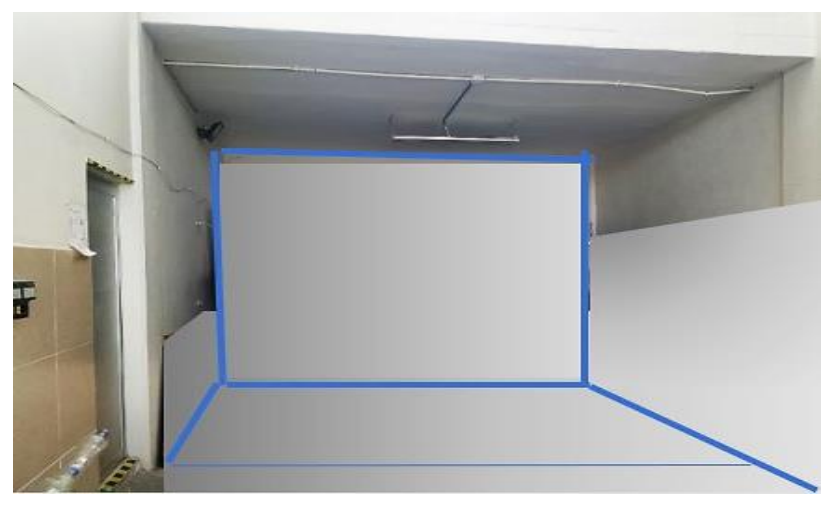

Figura 21 Interior del edifico K, Taller de Navales Fuente: elaboración propia

El espacio contempla una superficie de 16 metros cuadrados distribuida en las diferentes áreas manteniendo áreas "limpias" y sucias separadas. La zona "sucia" consta de las áreas de recepción y limpieza, licuado y secado de la materia prima; mientras que en la zona limpia se encuentra el área de humectación, prensado, secado y almacenado del producto terminado. 
Las dimensiones de cada de una de las áreas fueron calculadas para facilitar el movimiento a los estudiantes / operadores y garantizar los aspectos ergonómicos.

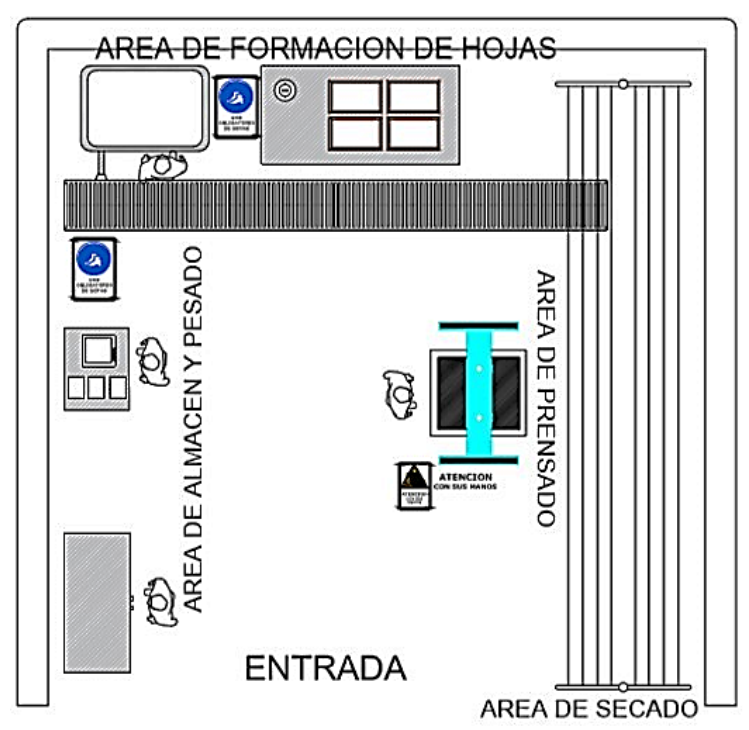

Figura 22 Lay out de la distribución del taller Fuente: Elaboración propia

\section{Costo de maquinaria y equipo}

En la tabla 1 se tienen los costos de maquinaria y equipo, considerando precios muy accesibles, equipos de muy buena calidad y eficientes.

\begin{tabular}{|l|r|}
\hline Denominación & Costo en pesos (\$) \\
\hline Balanza 40 kg. capacidad & 600.00 \\
\hline Tanque para moldeado 102 L. & 350.00 \\
\hline Licuadora industrial 10 L. & $7,000.00$ \\
\hline Prensa hidráulica manual 10 T. & $4,500.00$ \\
\hline Marcos y mallas & 250.00 \\
\hline Láminas de aluminio (20) & 100.00 \\
\hline Tela de lienzo (3 m.) & 50.00 \\
\hline Casillero & $4,000.00$ \\
\hline Utensilios en general & $3,000.00$ \\
\hline TOTAL & $\mathbf{1 9 , 8 5 0 . 0 0}$ \\
\hline
\end{tabular}

Tabla 1 Costos de principales equipos / utensilios Fuente: Elaboración propia

En la tabla podemos observar los precios de los equipos y utensilios para la recicladora, todos ellos ya tienen incluido el IVA. Se cotizaron en diferentes tiendas donde se consideró mejores precios y calidad de cada uno de ellos, empresas ubicadas en México y en su mayoría ya incluyen el costo de envío.

\section{Taller reciclador de papel}

El papel artesanal es el fabricado "hoja a hoja" por el artesano, a diferencia de la formación en continuo típica de la industria. Se puede fabricar con celulosa virgen o reciclando otros papeles y agregándoles fibras naturales. Entre sus características principales se puede citar la ausencia de un sentido o dirección de fibra predominante y la presencia de formaciones irregulares en sus bordes, lo que le añade una rusticidad muy apreciada en el mercado. El papel hecho a mano suma a su utilidad, la belleza de una pieza única.

En la actualidad el papel artesanal posee aplicaciones especiales en las que no compite con el industrial. Su forma de elaboración posibilita el agregado de pétalos, hierbas y un sinfín de elementos decorativos y puede ser aplicado en lámparas, mamparas, sobres, estuches, agendas, tarjetas, cuaderno, folder y álbumes o como soporte del dibujo y la pintura.

Es un proceso artesanal combinado con la parte industrial, teniendo como prioridad fomentar la sustentabilidad y así cuidamos al medio ambiente, siendo nosotros mismos (académicos y estudiantes) partidarios en este trabajo para disminuir la contaminación.

Considerando cada detalle y con respecto a los costos se consideraron más factibles los siguientes equipos $y$ sus respectivas características de cada uno de ellos.

\section{Metodología}

La metodología es de carácter descriptiva propositiva, toda vez que se conozcan las causas de la problemática y se dé una solución, las preguntas planteadas y los objetivos, direccionarán las etapas del trabajo. Se analizarán y se describirán datos, sobre el tema de investigación.

De tipo proyecto - documental porque, para su fundamentación se obtendrá la información de diversas fuentes escritas (textos, revistas, periódicos, monografías y tesis que tengan relación con el tema o motivo de investigación). 
Tiene un enfoque cuantitativo porque procura conocer y valorar los resultados para diagnosticar adecuadamente el problema y encontrar soluciones a través de la técnica descrita incursionando su importancia, beneficios $y$ herramientas $o$ equipos involucradas en el proceso de manufactura artesanal.

\section{Anexos}

Las figuras del 23 al 33, permiten considerar los elementos básicos para el inicio de un proyecto académico con impacto a capacitar a pequeños productores o habitantes de colonias marginadas para su autosuficiencia económica.

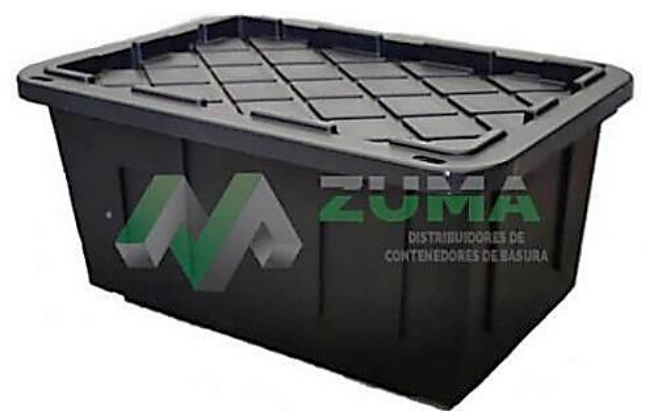

Figura 23 Caja multiusos 102 de 78 x 52 x 36 . cm con capacidad de 102 litros (27 galones)

Fuente: https://gavetasdeplastico.com.mx/

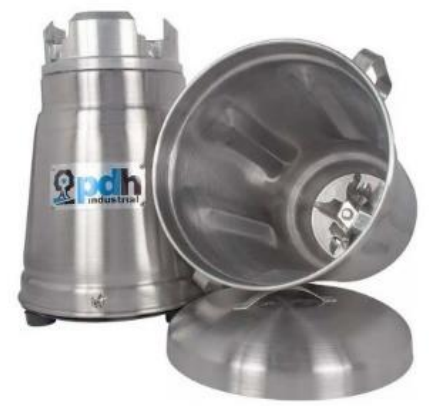

Figura 24 Licuadora industrial PDH, 10 litros Fuente: Turmix

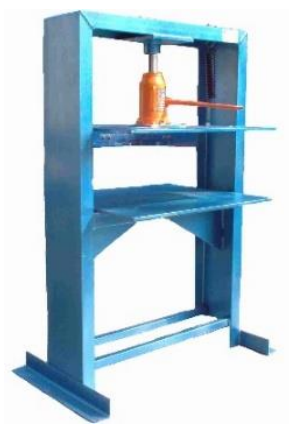

Figura 25 Prensa hidráulica manual Modelo 70/80, con bases de $700 \mathrm{~mm} \times 800 \mathrm{~mm}$, espesor de 3/8", plancha de $700 \mathrm{~mm}$ x $800 \mathrm{~mm}$. Placa de 1/2" con gato hidráulico de 10 ton presión

Fuente: https://www.aceroarte.com

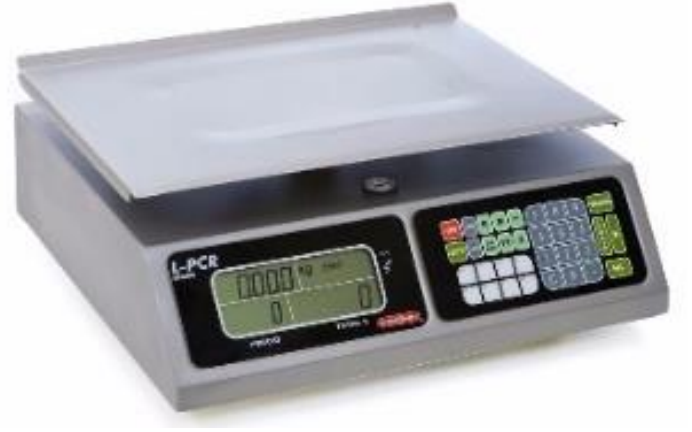

Figura 26 Báscula digital comercial de mesas, de $40 \mathrm{~kg}$ de capacidad, recargable doble pantalla Fuente: Aratsa Pop

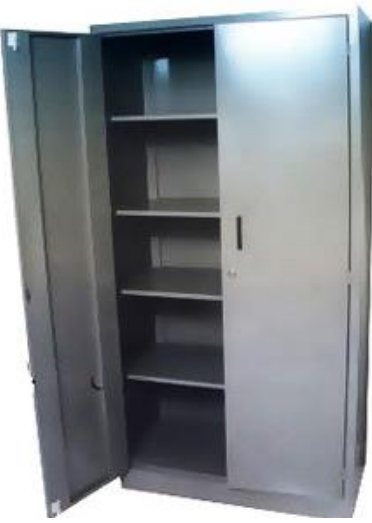

Figura 27 Gabinete metálico alacena

Fuente: https://www.officemuebles.com.mx/

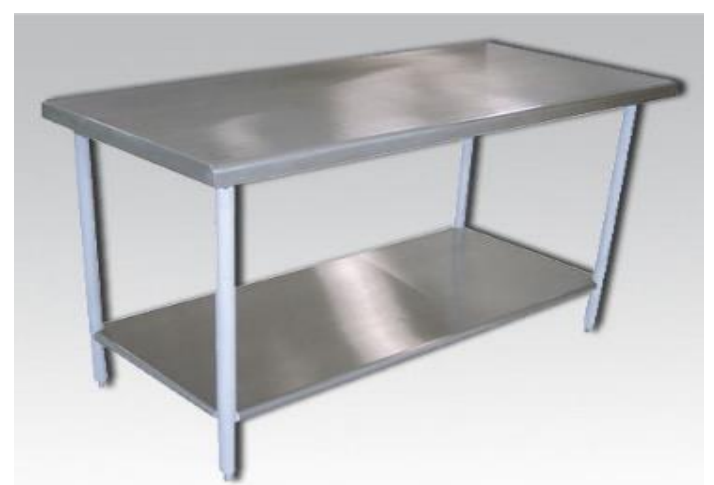

Figura 28 Mesa de acero inoxidable BLAZER MAI 24 x 48 pulgadas

Fuente: (INMEZA)

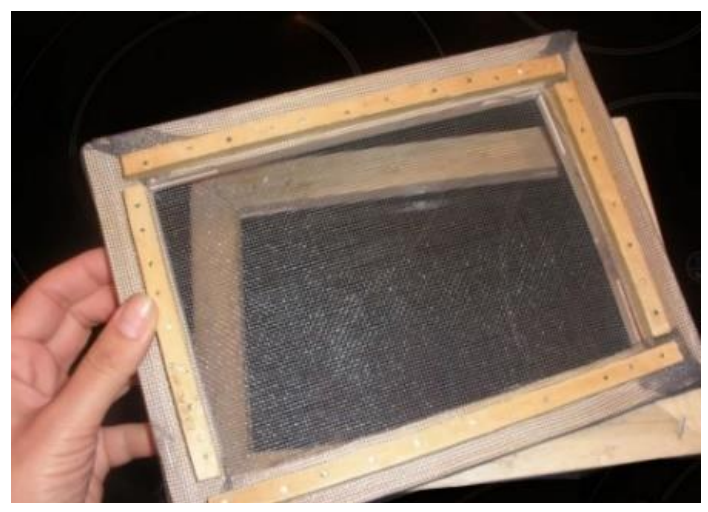

Figura 29 Bastidor / marco para reciclaje de papel Fuente: https://www.bioguia.com/

RAMÍREZ-ROMÁN, Adolfo, SUÁREZ-ÁLVAREZ, Ángel, RODRÍGUEZ-RODRÍGUEZ, Luis Alberto y CHABAT-URANGA, Jacqueline. Manufactura artesanal de papel. Revista de Ingeniería Industrial. 2020 


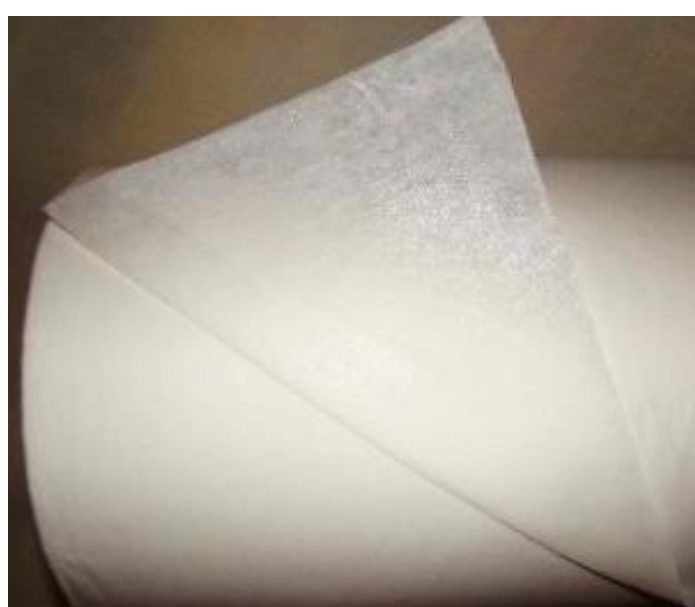

Figura 30 Rollo de tela tipo pellón Fuente: https://montblan.mx/

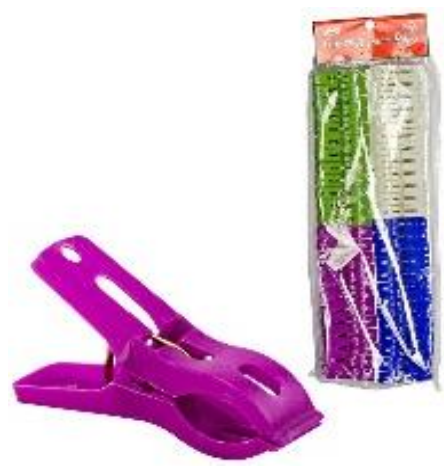

Figura 31 Gancho para ropa básico Fuente: https://guateplast.net

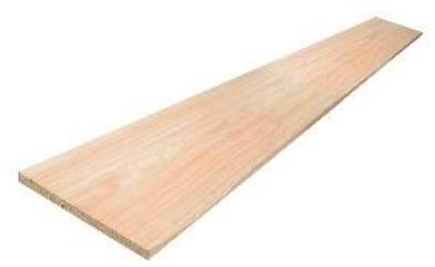

Figura 32 Pieza de madera de 50 x $30 \mathrm{~cm}$ x 1" de espesor Fuente: http://www.grupomaderero.com/

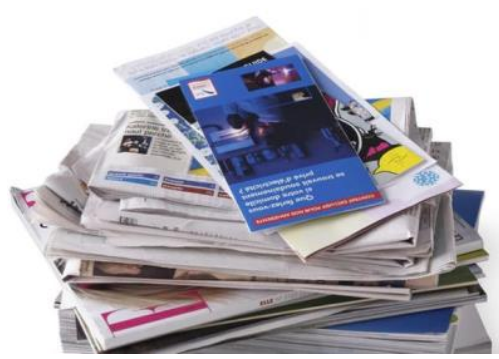

Figura 33 Papel desechado y reutilizado Fuente https://www.renovablesverdes.com

\section{Agradecimiento}

La gestión del personal directivo y administrativo de la Facultad de Ingeniería Mecánica y Ciencias Navales, e integrantes del Cuerpo Académico UV-CA-470 Innovación en Sistemas de Gestión y la invaluable gestión académica del Mtro. Jorge Eulogio Rodríguez Rodríguez y de la estudiante tesista Blanca Liz Olguín Muñoz (ZS15021607) por su aportación en el desarrollo del proyecto de implementación.

\section{Conclusiones}

Las investigaciones de campo realizadas en el periodo de agosto - diciembre de 2019 para garantizar la factibilidad de recicladora de papel artesanal fueron pertinentes, obteniendo datos técnicos y económicos de cada maquinaria y utensilios para un uso académico y de formación para micro, pequeña y mediana empresas de la región a través del programa institucional de formación dual de la Coordinación de Vinculación de la Facultad. También se tomaron las medidas correspondientes para la localización de dicho taller con 16 metros cuadrados para la implementación con una ubicación adecuada no afectando las áreas operativas del taller de navales y de ingeniería industrial ubicados en el Edificio $\mathrm{K}$, mucho menos al medio ambiente.

La inversión del proceso de manufactura de la recicladora de papel artesanal es de $\$ 19,850.00$ con IVA incluido, teniendo en cuenta que se cotizó equipos de calidad y que se les pudiera dar otro uso no solo para la recicladora de papel, siendo así el caso de la prensa hidráulica para actividades académicas en el programa educativo de Ingeniería Mecánica y taller de tornos, pruebas mecánicas y de materiales. Es factible por fomentar cultura del reciclaje y también producción económica en el entorno como un proyecto a corto plazo.

Se ejecutaron investigaciones sobre el uso inadecuado de los diferentes tipos de residuos para visualizar la forma de contribuir al cuidado del medio ambiente, también, la materia prima es un residuo con mucho consumo no solo en el país, sino en todo el mundo, por ello, se enfoca fomentando las actividades manuales para desarrollar la psicomotricidad en estudiantes, académicos y asistentes. 
A través del trabajo se tendrá un espacio para la aplicación de los conocimientos teóricos adquiridos en clases y complementario con laboratorios y taller de los programas educativos de ingeniería industrial e ingeniería mecánica eléctrica.

\section{Referencias}

Agua de la Roza, J. (2020). Manufacturas, caridad y salario en la red asistencial madrileña del setecientos. Mediterranea - ricerche storiche, (48).

Agricultura ecológica. Naturvegan Ecologico S.L. https://www.ecoagricultor.com/ (Consultado el 20 de septiembre de 2019)

Barbé Arrillaga, Juan (2017) Las Plantas y su papel. 102 recetas papeleras. 978-84-16209-842. HiFer Editor.

BBC News Mundo. (8 de Julio de 2019). Crisis mundial de la basura": 3 cifras impactantes sobre el rol de Estados Unidos. (C. ( ). BBC, Ed.) BBC News Mundo, 2. Obtenido de https://www.bbc.com/mundo/noticias48914734

Berger Grigoletto, I. C. (2012). Reaproveitar E Reciclar O Papel: Proposta De Conscientização Da Preservação Ambiental. Revista Monografias Ambientais, 6(6), 1414-1422. https://doi.org/10.5902/223613084616

Cámara Nacional de las Industrias de la Celulosa y del Papel (http://www.camaradelpapel.mx).

De Castro Faria, Á. B., Camargo Angelo, A., \& Garcia Auer, C. (2015). Disponibilidad de macronutrientes de eucalyptus saligna cultivado con lodo de papel reciclado. Floresta, 45(2), 261-271. https://doi.org/10.5380/rf.v45i2.26506

\section{El Museu Molí Paperer de Capellades. Fundado} $1958 . \quad$ http://www.mmpcapellades.net/spa/informacion.html (página electrónica consultado el 16 de octubre de 2019)

Flores - Montes, J. (2020). Mercancías únicas. La fantasía ideológica de la producción de textiles artesanales. Liminar, 18(1).
García Velásquez, L. Y. (2020). Diseño del Sistema Documental para la Implementación de las Buenas Prácticas de Manufactura en la Empresa Crikiconos SAS Zomac, Ubicada en Tauramena-Casanare

Guarin, A. S., Molina, J. S., \& Mendoza, J. A. G. (2020). Retos y tendencias del sector cerámico artesanal de Cúcuta y su área metropolitana. Respuestas, 25(1), 67-79.

H., L. (2001). Historia del papel en México y cosas relacionadas: 1521-1950. México, D.F.: Porrúa.

Infante-Alcalde, J., \& Valderrama-Ulloa, C. (2019). Análisis Técnico, Económico y Medioambiental de la Fabricación de Bloques de Hormigón con Polietileno Tereftalato Reciclado (PET). Información Tecnológica, 30(5), 25-36. https://doi.org/10.4067/S0718-

07642019000500025

Inforeciclaje. (s.f.). www.inforeciclaje.com. Obtenido de http://www.inforeciclaje.com/reciclajepapel.php

Joseph. (2004). El papel. Técnicas y métodos tradicionales de elaboración. Barcelona: Parragón Edicione.

Lavinia, A. (2017). Creadora de zapatos de papel reciclado. Entrepreneur Mexico, 25(12), 120.

M., Á. R. (2001). Productos forestales no madereros en América Latina. Santiago de Chile. Obtenido de http://documentacion.sirefor.go.cr/archivo/pfmn /Pfnm.pdf

Mexicana, N. (2010). www.camaradelpapel.mx. Obtenido de http://camaradelpapel.mx/pdf/Normas/NMX-N107-SCFI-2010ACT.pdf

Norma Mexicana NMX-N-107-SCFI-2010. Industrias de celulosa y papel - contenido mínimo de fibra reciclada de papel para la fabricación de papel periódico, papel para bolsas y envolturas, papel para sacos, cartoncillo, cajas corrugadas y cajas de fibra sólida especificaciones, evaluación de la conformidad y eco-etiquetado. Secretaria de Economía. 
Organización de las Naciones Unidas - ONU. (2019). www.un.org. Obtenido de https://www.un.org/sustainabledevelopment/es/ objetivos-de-desarrollo-sostenible/

Paperlan, empresa particular (2000) Fabricación y venta de Papel a Mano. http://paperlan.com/ (consultada 4 febrero 2020)

Restrepo Castro, A. C. (2020). Manual Práctico de Manufacturación Artesanal de Dietas Acuícolas Alternativas para Cachama Blanca Piactus brachypomus, Cuvier 1818, Dirigido a Acuicultores de Recursos Limitados de los Municipios de Lejanía y el Dorado, Meta.

Rodríguez-Bruceta, P. A., Pérez-Rodríguez, Á. T., \& Velázquez-Infante, J. C. (2015). Propuesta de un procedimiento para el reciclado del polietileno de alta densidad. Revista Cubana de Química, 27(1), 32-54.

Salinas López, G. A., Victoria Moreno, A., \& Osorio Gómez, J. C. (2013). Impacto Del Material Reciclado en Los Inventarios De Materias Primas De Una Empresa Manufacturera. Revista EIA, 19, 91-101.

Saucedo, J. T., Poblet, M. P., Suárez, E. G., Saucedo, A. R., \& Ramos, S. P. (2001). Obtención de papel para corrugar a partir de diferentes mezclas de fibras alternativas. Centro Azúcar, 28(2), 85-92.

Secretaria de Medio Ambiente y Recursos Naturales - SEMARNAT, S. d. (2006). Estadísticas Nacionales. Anexo del Sexto Informe de Gobierno 2006. Primer informe de gobierno.

S., M. M. (2004). Papel de madera. Una reflexión sobre la productividad y uso del papel en México. Revista electrónica de la Comisión Nacional Forestal.

T., E. G. (2006). Manual de Fabricación papel hecho a mano, amate y papiro. (Método TeoCart). Zapopan, Jalisco, México: DMCyPUdG.

Tappi (2007) Official Test Methods, Technical Association of the Pulp and Paper Industry
Teschke, K. (2001). Industria del papel y de la pasta de papel: Importancia económica. (Vol. 3). Enciclopedia de Salud y seguridad en el trabajo.

Tlaquepaque, t. y. (s.f.). Obtenido de http://web.a.ebscohost.com/ehost/detail/detail?v $\mathrm{id}=2 \&$ sid $=$ da1 16016-2444-49b6-b60d-

$577 \mathrm{ec} 7 \mathrm{c} 8 \mathrm{c} 287 \% 40$ sessionmgr4006\&bdata $=\mathrm{JkF}$ 1dGhUeXBIPWlwLHVybCx1aWQsY29va211J mxhbmc9ZXMmc210ZT1laG9zdC1saXZl\#db= a9h\&AN=28601299

Turrado, J., Saucedo, A. R., Ramos, J., \& Reynoso, M. L. (2008). Comportamiento de la Fibra de Celulosa Reciclada en el Proceso de Hidratación. Información Tecnológica, 19(5), 129-136.

https://doi.org/10.1612/inf.tecnol.3955it.07 